\title{
There Can Be No Moral Obligation to Eradicate All Disability
}

\author{
REBECCA BENNETT
}

John Harris argues that "it may be morally wrong to 'choose' to bring to birth an individual with any impairment, however slight, if a healthy individual could be brought to birth instead." 1 This is a strong and controversial statement but one that, at least initially, seems to fit with many people's intuitions about what sort of children to have, given the choice. It taps into our shared desire to protect our children where possible and give them as many opportunities as we can. Most of us would choose that our child be not disabled, and these shared intuitions and preferences to have children who are as "perfect" as possible seem to support Harris's claim.

However, it is important to explore Harris's claim more fully. The reason that this claim must be further examined is that it is important to recognize that Harris's claim is not about choosing the best for our children but about choosing which children it would be better to bring to birth. It is uncontroversial to say that we should do the best we can to enhance the welfare of existing people, particularly our own children. It is quite another claim to say that we should take steps to choose which children should be born, not because we worry about these children's welfare but because we want to make what we consider to be a better society.

In this article I show that, despite Harris's overt commitment to equality, ${ }^{2}$ this claim, if accepted, unavoidably confers a lower value on the disabled or impaired. If we have a moral obligation to choose against individuals with disability, not because of a concern for their own welfare but because a world without disability is a morally preferable place, then this inevitably places a lower value on those living with disabilities. The good news is that Harris cannot justify his claim, and thus the unappealing consequence of this claim can be dismissed with his argument about a moral obligation to have the best child possible. But exposing the flaw in Harris's argument is important; otherwise we are left with an intuitively appealing argument from a well-respected thinker that has consequences that are not only unappealing but offensive and dangerous if they become the basis for policy.

\section{Harris's Position}

There is a strong argument to suggest that we have a moral obligation to choose not to bring to birth individuals who will have lives overwhelmingly dominated by suffering. In such cases it seems that life is not a benefit to these individuals, as the positive aspects of life are missing either due to the lack of any mental capacity (e.g., anencephalic infants) or as a result of extreme suffering that completely 
outweighs any expected positive experiences. Clearly, a judgment about what counts as a life that is unworthwhile, that is, one in which suffering is expected to outweigh any positive features of life, is a difficult one to gauge. However, what is clear is that those born with conditions such as deafness and many other "disabling" conditions would not be predicted to have lives that were unworthwhile in this way.

Therefore, taking deafness as our example, if deaf individuals are expected to have lives of value, worthwhile lives, then in what sense could it be wrong to bring such worthwhile lives into being? Harris argues that prospective parents have a moral obligation to avoid disability where possible. ${ }^{3}$ Thus, if, for example, a couple is attempting to reproduce by IVF and a choice will have to be made about which embryos to implant, then, according to Harris, preimplantation genetic diagnosis (PGD) should be used to inform this choice and to avoid disability wherever possible. The nature of this alleged wrong of bringing to birth a disabled child is complex. As long as the resultant child is likely to have a life worth living, Harris argues that the child cannot have been wronged by being brought to birth, as he has benefited from his existence (of course, whether someone can be benefitted from being brought to birth is debatable). ${ }^{4}$ But if the child has not been wronged by being brought to birth, what sense can be made of the claim that the choice to do so is morally questionable or even wrong?

Harris considers the example of a congenitally deaf couple who, after undergoing IVF, are faced with a choice of embryos to implant. We are asked to suppose that preimplantation screening has shown that among the embryos available for implantation are two congenitally deaf embryos. Harris claims that to choose to implant the deaf embryos rather than the "healthy" embryos would be morally wrong. He argues that "in a case like this the parents have wronged no one, but have harmed some children unnecessarily, but those who were harmed had no complaint because for them the alternative was non-existence." ${ }^{5}$ Harris argues that if it is possible for a parent to have a child who is not disabled, and if that parent chooses to bring to birth a disabled child, the parent is choosing to bring disability into the world. On this view the choice to bring to birth a "disabled" child is partly wrongful because it causes a child to be born in a "harmed" condition and partly wrongful because it creates a world that needlessly contains more suffering, hardship, or disability than would have been created by an alternative choice. ${ }^{6}$

\section{Harmed Conditions and Better Worlds}

There are a number of problems with Harris's analysis here. First, it is, of course, impossible to agree on what constitutes the "best" life. Some people prioritize happiness over intelligence, others value physical well-being and longevity, and others would see good looks as essential. What is the best child is a very subjective judgment. ${ }^{7,8,9}$ Second, Harris does not explore in any real detail the theoretical foundations of his controversial arguments on this issue. We are thus left, to some extent, to guess what the reasoning behind these arguments is. Finally, he mixes together person-affecting issues with non-person-affecting issues, which makes the problem difficult to pin down and allows flawed arguments to have intuitive power.

Leaving aside for now the practical problem of agreement over what might constitute the best life, let us focus on Harris's justification for his claims about this 
moral obligation to bring to birth the best children possible. As we have seen, he argues that choosing to bring to birth a disabled rather than a nondisabled child is wrong on two counts: first, it causes a child to be born in a "harmed" condition, and second, it creates a world that is "worse" than it needs to be, a world with more suffering in it than the alternative.

\section{In What Sense Are Those Born with a Disability Harmed?}

Remembering that we are talking about disabilities such as deafness in which the individual concerned is expected to have a worthwhile life, what sense can be made of Harris's claim that disability necessarily involves suffering and that those who are born disabled are therefore born harmed? Does it make sense to say that the deaf suffer as a result of their deafness?

Harris argues that living with a disability is in itself necessarily a harm. For instance Harris argues that "to be harmed is to be put in a condition that is harmful. A condition that is harmful . . . is one in which the individual is disabled or suffering in some way or in which his interests or rights are frustrated." 10 So for Harris bringing to birth a disabled child is wrongful because it "causes a child to be born in a "harmed condition."'11 Harris accepts that the impaired child has "no complaint because for them the alternative is non-existence ${ }^{\prime 12}$ and thus although the child is not wronged by the choice to bring him to birth, those choosing to bring this child to birth are responsible for harming this child and causing this child to suffer from this harm.

When explaining the wrong of denying a deaf child a cure, Harris argues:

Would the child have any legitimate complaint if they did not remove the deafness? Could this child say to its parents: "I could have enjoyed Mozart and Beethoven and dance music and the sound of the wind in the trees and the waves on the shore, I could have heard the beauty of the spoken word and in my turn spoken fluently but for your deliberate denial."13

Harris would argue that existing with disabilities such as deafness is clearly "worse" than existing without these disabilities. Otherwise why would we attempt to develop cures for deafness at all, and why would it be wrong to deafen a hearing child? ${ }^{14}$ He continues and shows just how much of a moral wrong he thinks bringing to birth a deaf child is by arguing, "I do not believe there is a difference between choosing a preimplantation deaf embryo and refusing to cure a newborn. Nor do I see an important difference between refusing a cure and deliberately deafening a child." 15 Thus, for Harris, the moral wrong done by bringing to birth a deaf child is a serious moral wrong, as wrong as deafening a hearing child.

But this is the clever but flawed bit of the argument. Of course we can see that deafening a hearing child or denying a child an available cure for deafness is morally wrong. On the basis of this, Harris will then argue that if this is wrong, it is because deafness is a harm, and thus creating a deaf child creates a harmed child and is equally morally wrong. In both cases a deaf child is created that need not have been.

However, there is a problem with this analogy and this argument about harming. The situation of deafening the hearing child is a very different situation from 
the child brought to birth with congenital deafness. Although it is true that both these choices result in a deaf child being created, these are very different acts. We can understand this further if we consider the notions of person-affecting and non-person-affecting harm.

\section{Person-Affecting and Non-Person-Affecting Harm}

Derek Parfit was also drawn to this notion that we might have a moral obligation to choose to bring to birth the best children possible, and Harris is clearly influenced by Parfit's work in the examples he gives to support his claims. Parfit discusses what he calls the "person-affecting intuition," 16 which describes the commonsense everyday notion of harm and benefit, in which harm and benefit are comparative notions. So this is the view that an act harms someone because it makes them "worse off" than they would have otherwise been or benefits someone by making them "better off" than they would otherwise have been. These acts affect a particular person, changing his or her welfare, making him or her worse or better off than he or she would otherwise have been; thus they can be described as person affecting. Non-person-affecting harm, or what Parfit terms "impersonal harm,"17 goes against this comparative view of harming. The idea of this impersonal harm is that it does not affect the welfare of any particular individual but causes there to be less, generally, of what makes the world a good place to be. This notion of impersonal harm is based on what Parfit calls the "Impersonal Total Principle," which says that "if other things are equal, the best outcome is the one in which there would be the greatest quantity of whatever makes life worth living."18 Non-person-affecting or impersonal harm does not make any individual worse off but may be considered to make the world a worse place, as it will contain less of what makes life worth living.

To understand these different notions of harm, it is helpful to identify examples of these kinds of harm in Harris's earlier analogy. Deafening a hearing child makes a particular person worse off than he or she needs to be, as does denying a deaf child an available cure. These are both examples of person-affecting harm. This child would have a legitimate complaint to say, "But for your actions I could have been able to hear, an opportunity that is likely to enhance my welfare."

However, bringing to birth a congenitally deaf child is a very different situation. The congenitally deaf child is born in the only condition she can be born in. She is not made worse off by this choice to bring her to birth, and she is likely to have a worthwhile life. She does not have the same cause for complaint as does the child who is deafened, because the choice to bring her to birth did not cause her to lose her hearing: it was never there to be lost. She is not made worse off by this choice. Thus, if there is any harm incurred by this action, it cannot be said to be personaffecting, as no individual's welfare is affected by this choice.

So this is the reason why Harris's analogy doesn't work. These are very different notions of harming. Harris is claiming that a disability, such as deafness, is a harm in itself and that this is demonstrated by the fact that we would think it immoral to deafen a hearing child or deny a deaf child an effective cure for deafness. But from our analysis we can see that it is not that deafness is a harm in itself that makes these acts immoral. Being deaf is not likely to cause this child to have a life of unbearable suffering. Given appropriate support and introduction to deaf culture, he is likely to have at least as rich a life as any hearing individual, and 
Harris would be the first to accept this. Rather, the harm involved with deliberately deafening someone results not from deafness itself but from being denied hearing when hearing was a possibility. The harm occurs as a result of deliberately denying people things that they desire. Thus, if we assume that most people wish to hear, then to deliberately deny them this desire would be morally wrong. It is the thwarting of individual choices that is morally questionable here. Would we feel it morally important to put pressure on a competent deaf adult to accept a cure for his deafness if he refused it? I would argue we wouldn't, as even if we feel he suffers from deafness, if it is clear that he prefers not to be cured, then this choice about his life should be respected. However, because the majority of people probably see deafness as a harm and would prefer not to be deaf, we would feel it important-when a competent objection is not made - to cure deafness where possible and to avoid deliberately deafening individuals. This decision is not made because we think that being deaf is an intolerable existence; rather, it is made because we should not deliberately deny individuals a physical attribute we can generally assume they would wish to have. We should not act to make people worse off than they could have been if we had acted otherwise.

However, the wrong involved in deafening a hearing child or denying a child a cure for deafness is not present in the act of choosing to bring to birth deaf fetuses. The result is the same-a deaf individual exists who would not have existed without these actions. But as the wrong in the first case is of decreasing the welfare of a particular individual by closing off options that this individual may desire, this wrong is not present when no options are closed off. By choosing to bring to birth deaf fetuses, we do not deliberately deny someone options/experiences. We are talking about a choice of bringing to birth two different fetuses-one who will be deaf and one who will not. To choose to implant a deaf embryo rather than a hearing one is not to deny that deaf child anything he could have had. He can either be born deaf or not at all, and to be born deaf is to be born with a life expected to be as worthwhile as any other. Harris accepts that a child born with deafness is likely to have a worthwhile life, a life he is as likely to value as anyone else. There is no person-affecting harm here. No individual's welfare is damaged by this choice, unlike the case of deafening a hearing child.

Thus, if the choice to bring to birth a child with congenital deafness can be considered a harm, it is not a harm to that child. However, despite this analogy not actually being analogous, Harris's use of it is very clever. We feel there is something intuitively wrong with the choice to have a deaf child over a hearing child. We also can see that deafening a hearing child is morally wrong; it's harmful to that child. So when we put these two things together, we appear to have a reason for our unease about the choice to implant a deaf IVF embryo, if we suppose that the harm done in deafening the hearing child is that it is deafness itself that is a harm. So in reply to my claim that we do not harm someone by bringing them to birth with an impairment like deafness or a predisposition to cancer, Harris might say, "So if being born in such an impaired state is okay, you won't mind if I deafen your child then, or remove funding for cancer treatment." But as I have shown, because of this difference between person-affecting and non-person-affecting harm, when we look beyond these surface intuitions, this is no longer as convincing as it first appears. Although we may feel uneasy about choosing to implant a deaf IVF embryo over a hearing one, this cannot be because we do something to the individual whom the deaf embryo, or the embryo with a predisposition to 
cancer, will become that he could have reason to complain about. He is born in the only state in which he can be born and is as likely as anyone else to have a worthwhile life. He is not harmed by this choice. Deafening a hearing child or denying someone cancer treatment is a completely different situation, however, one in which a particular individual is harmed by our actions and does have reason to complain.

As a result, we are left with a situation in which, at least on person-affecting considerations, there can be no moral obligation to choose to have the best child possible. Thus if we are worried about the welfare of individuals, we do not have a moral imperative to avoid bringing to birth disabled individuals in order to prevent the deliberate frustration of desires, as the congenitally deaf could not be born in any other state, and their welfare is not affected by this decision. We do not have a moral obligation to avoid bringing to birth disabled individuals because these individuals will not have a worthwhile life, as the deaf and other disabled individuals are likely to have as worthwhile lives as any other. As a result, Harris needs to look elsewhere if he is to find a reason that supports his claim for this obligation to bring to birth the best children possible.

\section{Non-Person-Affecting or Impersonal Harm}

Parfit would agree with my analysis of person-affecting harm, but instead of deciding that there cannot be a moral obligation to bring to birth the best children possible, he postulates another kind of harm, non-person-affecting or impersonal harm, that might justify our intuitions about these choices. This kind of harm is not something that affects the welfare of individuals, but the idea is that if society is made up of individuals who have a lower quality of life than they could have had if they were hearing, more intelligent, better looking, more optimistic, or whatever we decide makes the "best" life, then the cumulative totals of whatever makes the best life will be lower in these societies than in other possible societies. These societies will have more impersonal harm in them than they need to, even though this free-floating impersonal harm does not attach to a particular individual.

To try and understand this notion of non-person-affecting harm or impersonal harm, let's consider two possible alternative worlds. Suppose in both worlds reproductive technology is such that it is possible, without any problematic intervention, to avoid bringing to birth individuals we believe will have lives that are not worthwhile-lives that would be considered of overwhelming negative value, either because of lack of cognitive function or because they are completely dominated by suffering. Although the worlds are similar in this respect, they differ in another respect: in one possible world, A, fetuses who will have "disabled" but worthwhile lives are brought to birth, whereas in possible world B, these fetuses are not brought to birth. For Harris possible world B will be a better world, a world that contains less suffering and a world toward which we have a moral imperative to strive wherever possible. But as both worlds contain only individuals with worthwhile lives, and based on this we can assume that similar proportions of these individuals value these lives, how could we have a moral imperative to choose world B over world A? What would explain our intuitions that we should prefer world B? Why would one world containing only worthwhile lives be morally preferable to another world containing only worthwhile lives? 
As we have seen, Harris's answer to this question is that world A contains more suffering than world $\mathrm{B}$, and as we have a moral imperative to avoid suffering where possible, then, given the choice, we should choose world B. As we have also seen, this cannot be because of any person-affecting harm or suffering, as it makes no sense to claim that individuals born in the only state they can be born in and with worthwhile lives are harmed or suffer as a result of this action to bring these individuals to birth. So this must be non-person-affecting harm or suffering, an increase in the cumulative total of harm or suffering that is in this world. This is the suggestion that Parfit also postulates. However, there are serious problems with this notion of impersonal harm, to the extent that Parfit is unable to defend this concept.

\section{Problems with the Notion of Impersonal Harm}

There are well documented and discussed problems with the notion of impersonal harm. To start, although it is postulated to explain our intuitive response to cases that we feel uneasy about but that do not involve person-affecting harm, we find this concept difficult to accept on an intuitive level. It is difficult to understand how something can be wrong if it doesn't affect the welfare of any individual. If this harm doesn't have any effect on anyone, then in what sense can it be called harm?

On a more theoretical level, the notion of impersonal harm raises a number of serious difficulties, probably the most serious of which being what Parfit termed the repugnant conclusion. ${ }^{19}$ If what matters is to increase the cumulative totals of happiness or whatever makes life good in any given society, then this leads to some rather unpalatable conclusions. It appears to entail a moral obligation to reproduce, as the more worthwhile lives are created, the higher this cumulative total of good things will be. This again seems very counterintuitive and even more so if we take this to its ultimate conclusions. As Parfit explains: "For any possible population of at least ten billion people, all with a very high quality of life, there must be some much larger imaginable population whose existence, if other things are equal, would be better, even though its members have lives that are barely worth living." 20 This is the repugnant conclusion. According to these cumulative measures of impersonal good and harm, then, a huge population of low-quality but worthwhile lives would be considered morally preferable to a smaller population with a higher quality of life. Again, this makes impersonal harm a highly counterintuitive attempt to solve a problem of counterintuition. As Parfit makes clear, if we wish to invoke a notion of impersonal harm in our arguments, then we must solve the difficult problems that impersonal harm raises. ${ }^{21}$ Although there have been numerous attempts to solve these problems, these attempts are highly problematic, often raising as many problems as they solve. $22,23,24,25$ Furthermore, Harris has not examined this notion of impersonal harm in any detail or attempted to solve the serious problems associated with this notion of harm. ${ }^{26}$

\section{Does This Matter?}

So Harris's views on this notion that we have a moral imperative to choose the best child possible and thus move toward eradicating disability are based on a notion of harm that is counterintuitive and that has not been explored and defended 
by Harris. This leaves Harris's claim about this moral obligation unjustified and supported by intuition and a clever but ultimately flawed analogy.

But does this matter? Many of us share Harris's intuition that we have an obligation to bring to birth the best child possible and would prefer to have a child with the fewest impairments as is possible. So even if Harris's argument is not a philosophically robust one, isn't the fact that many of us feel he is right about this enough? In a democratic society, if we share this intuition, surely this should have some weight and negate some of the philosophical weaknesses in this stance.

As I mentioned at the beginning of this article, the problem here comes when we explore the other implications of this proposed moral obligation to produce the best child possible. The problem here is that this obligation, if accepted, unavoidably places a lower moral value on the disabled, and this is not something we should take lightly. It certainly requires that those who imply this should explain and defend their stance, rather than simply relying on public feeling.

\section{Does a Moral Obligation to Bring to Birth the Best Child Put a Lower Moral Value on the Disabled?}

Being the nice man that he is, Harris sincerely objects to the accusation that his arguments in favor of a moral obligation to avoid producing disabled children imply that disabled individuals have less value than nondisabled individuals. In fact, he stresses that despite this obligation to avoid producing disabled individuals, "all persons are equal and none are less equal than others. No disability, however slight, nor however severe, implies lesser moral, political or ethical status, worth or value." 27 For Harris there are just simply such things as better and worse lives, but this does not imply a lower moral value to these lives. ${ }^{28}$ In line with this, he claims that "it makes sense to say that my life would be better if I were healthier, happier and more successful." ${ }^{29}$ For Harris, then, if it is possible to choose to bring to birth an individual who will have more abilities, more intelligence, more beauty, and so on, than an alternative choice of future individual, then we have a moral obligation to do so, but this does not imply that those who live with impairments are of a lesser moral value.

But, although Harris would never treat any individual as if he or she were of lesser moral value, his arguments do not send the same message. Let us return to the two possible worlds we considered earlier: possible world A, in which fetuses who will have "disabled" but worthwhile lives are brought to birth, and possible world B, in which these fetuses are not brought to birth and such impairments are eradicated. As we saw, Harris would argue that we have a moral imperative to move toward achieving possible world $\mathrm{B}$, a world in which disability is eradicated. However, as we have also seen, this is not because people in world A suffer or are harmed more than in world B; both worlds only contain worthwhile lives, lives that those living them are likely to value. The measure on which world B is superior is on the cumulative totals of what makes life go well. The more unimpaired lives in world B have more value in this calculation than the impaired lives in world A. The unimpaired lives are worth more in this moral calculation. They are more morally desirable.

Now, it may well be the case that some lives are, for many, more desirable than others. Many of us would prefer to be as intelligent, attractive, successful, rich, and so on, as is possible and would want the same for our children. However does this mean that a world in which everyone is "fortunate" in these sorts of ways is a 
morally better world than one that contains individuals with worthwhile but less than "optimal" lives? It may be that we prefer this first world for ourselves and our children, but is it a morally better world?

It is this assumption that possible world B is not just preferable for many but also a morally preferable world that is the fatal flaw in Harris's argument. Many of us may have a preference for creating a future world that does not contain congenital disability. But a moral obligation to have the best child possible must be based on the idea that, if faced with a choice between two future persons, both of whom will have worthwhile lives, we should choose the "most perfect" future individual, not simply because we have a preference for this kind of individual but because a world containing such individuals is morally superior to a world containing other less advantaged individuals.

It may well be that we would choose possible world B as a more preferable world if we had to make the choice between these two possible futures. However, I argue that, rather than having a moral reason to choose possible world B over possible world A (or to choose a hearing embryo over a deaf embryo), this choice is a morally indifferent choice. It may be that most of us would prefer to implant the hearing embryo rather than the deaf embryo or would think it more desirable to live in a world without disability, but this does not make it morally wrong to make a different choice. These are simply preferences about the sort of world we would like to live in and the sort of children we would like to have. As long as we are choosing to create worthwhile lives, whether we choose a fetus who will be deaf, hearing, "ugly," dyslexic, short, tall, highly intelligent, and so on, is not a moral choice. As long as we are choosing between fetuses that are expected to have worthwhile lives, whichever one we choose, no individual has been harmed by having the possible options available to that particular individual curtailed, and a worthwhile life has been created. A world has been created with individuals who perhaps have more obstacles in life than if other choices were made, but it is not the case that we could have created these particular individuals to be any other way than they are; we could only have created other individuals instead.

As we have seen, Harris offers no robust reasons for a moral preference for possible world B or for preferring to bring the unimpaired worthwhile life to birth over the impaired worthwhile life. His arguments that those born with a disability are harmed by being born in this impaired state do not stand up to scrutiny. No one is harmed or suffers by being brought to birth with a worthwhile, if impaired, life. The postulation of the abstract notion of impersonal harm does not go very far to improve the situation for Harris and, at least as it stands in this hinted at but underdeveloped state, does not provide any justification either.

What we are left with is a clever argument that appeals to our intuitions and preferences on these issues about reproduction but has offensive connotations and that when examined more closely turns out to be completely unjustified intuition. An unjustified intuition that has a strong eugenic message and infers a lower moral value on the disabled is something that we need to be concerned about.

\section{Can Harris Save His Argument?}

So, can Harris save his argument about this moral obligation to have the best child possible, or does he have to accept the conclusion that when we are choosing between worthwhile lives, these are morally indifferent choices? 


\section{There Can Be No Moral Obligation to Eradicate All Disability}

In order to save his argument, he would need to put forward a credible version of impersonal harm that avoided the problems that such a notion entails. This may or may not be possible, but it is the only thing that could provide the justification needed here. However, even if a credible notion of impersonal harm was presented, it would be still debatable whether impersonal harm has enough weight to outweigh the other undesirable consequences of Harris's arguments. Could an obligation to prevent impersonal harm, that is, harm that does not affect any individual, be enough to justify a stance that puts a lower moral value on the disabled? Furthermore, if a proposed obligation to bring the best child to birth were allowed to influence policy, it is likely to infringe on individual reproductive autonomy by requiring those undergoing IVF to choose whatever is considered to be the best embryo possible, regardless of that couple's views about choosing in this way. Is impersonal harm that does not change the welfare of any individual a strong enough reason to infringe on reproductive autonomy in this way?

Harris's only other option is to argue that disabilities such as deafness are such a harm that they render affected lives not worth living. His argument that those who are disabled suffer from this disability, as we have seen, just doesn't make sense on person-affecting grounds. But even if it did, even if Harris could convince us that the congenitally deaf suffer from their deafness, this does not help him. If we accept this and Harris's assertion that we have "a strong moral obligation to prevent preventable harm and suffering," 30 including the creation of new lives, then we surely must also accept what Harris would not accept, that reproduction is always immoral, as we are all subject to suffering through unavoidable physical and emotional pain.

\section{Conclusion}

Harris has established a strong body of work upholding his claim that we have a moral imperative to choose to bring to birth nondisabled children rather than disabled children, even if they are likely to have worthwhile lives. In this article I have shown that Harris's argument, although superficially strong, contains serious flaws. Harris does not provide a robust justification of these claims, and it is questionable whether such a justification is something that might be found. This matters because Harris's claim that we have a moral obligation to choose nondisabled future lives over disabled but worthwhile future lives confers a lower moral value on the lives of these disabled individuals. As Harris is passionately committed to the notion of moral, social, and political equality for all persons, this is an inference he would not accept, but it is an unavoidable inference from his arguments. Therefore, the challenge is now for Harris either to revisit the notion that disability is in itself a harm and his explanation for this and provide a robust justification for this obligation and the difficult inferences it presents, or to abandon his conclusion regarding our moral obligation to choose to bring to birth nondisabled children.

\section{Notes}

1. Bennett R, Harris J. Are there lives not worth living? When is it morally wrong to reproduce? In: Dickenson D, ed. Ethical Issues in Maternal-Fetal Medicine. Cambridge: Cambridge University Press; 2002:321-34, at 325 .

2. Harris J. One principle and three fallacies of disability studies. Journal of Medical Ethics 2001;27:383. 


\section{Rebecca Bennett}

3. See note 1, Bennett, Harris 2002.

4. Harris J. The wrongs of wrongful life. In: Clones, Genes, and Immortality: Ethics and the Genetic Revolution. Oxford: Oxford University Press; 1998:99-119, at 117.

5. Harris J. Is there a coherent social conception of disability? Journal of Medical Ethics 2000;26:95-100, at 97.

6. See note 4, Harris 1998, at 111.

7. See note 1, Bennett, Harris 2002.

8. Herrisone-Kelly P. Procreative beneficence and the prospective parent. Journal of Medical Ethics 2006;32:166-69.

9. Parker M. The best possible child. Journal of Medical Ethics 2007;33:279-83.

10. See note 4, Harris 1998, at 109.

11. See note 1, Bennett, Harris 2002, at 325.

12. See note 5, Harris 2000.

13. See note 5 , Harris 2000.

14. Harris J. Reproductive liberty, disease and disability. Reproductive Medicine Online 2005;10(1):14.

15. See note 5, Harris 2000.

16. Parfit D. The non-identity problem. In: Reasons and Persons. Oxford: Clarendon Press; 1987:352-79, at 363.

17. See note 16, Parfit 1987.

18. See note 16, Parfit 1987, at 378 .

19. See note 16, Parfit 1987 , at 388 .

20. See note 16, Parfit 1987, at 388.

21. See note 16, Parfit 1987.

22. Hurka T. Value and population size. Ethics 1983;93:496-507.

23. Kavka GS. The paradox of future individuals. Philosophy and Public Affairs 1982;11:93-112.

24. Feldman F. Utilitarianism, Hedonism, and Desert: Essays in Moral Philosophy. Cambridge: Cambridge University Press; 1997.

25. Temkin LS. Intransitivity and the mere addition paradox. Philosophy and Public Affairs 1987; 16:138-87.

26. Bennett $\mathrm{R}$. When intuition is not enough: Why the principle of procreative beneficence must work much harder to justify its eugenic vision. Bioethics 2013 July;10. Published online DOI: 10.1111/ bioe.12044.

27. See note 2, Harris 2001.

28. See note 1, Bennett, Harris 2002.

29. See note 1 , Bennett, Harris 2002, at 30.

30. See note 5, Harris 2000, at 31 . 